\title{
Notas do debate com Marli André sobre "Campo de Pesquisa na Formação de Professores"
}

\author{
José Rubens Lima Jardilino \\ Universidade Federal de Ouro Preto - UFOP \\ Ouro Preto, M.G - Brasil \\ E-mail: jrjardilino@ufop.edu.br \\ ORCID: https://orcid.org/0000-0003-2394-9465
}

$\mathrm{Na}$ Era dos impressos, antes da revolução do texto digital, era comum se fazer edições especiais e verdadeiras recensões da obra de um/a intelectual, em duas ocasiões, quando este/a completava 70 anos e se jubilava, ou de maneira póstuma, como é nosso caso neste editorial - consagrar um número especial do periódico comemorativo à obra de uma determinado intelectual. As revistas acadêmicas tinham essa prática, porém atualmente esta prática vem caindo em desuso. O presente número da Revista Brasileira de Pesquisa sobre Formação de Professores, por decisão unânime do seu Conselho Editorial Executivo, decidiu dedicar este número especial a obra de Marli Eliza Dalmazo Afonso de André, conhecida na academia como Marli André como se poderá perceber em boa parte dos escritos que se seguem vão, de maneira afetiva, assim nomeá-la.

A obra de um/a autor/a, localizada em um determinado campo científico, literário, humanístico, pode ser interpretada em seu conjunto quando ela está fechada. Assim a morte prematura de Marli André, nos motivou a homenageá-la em um número anterior deste periódico quando de sua morte, e, agora analisar sua trajetória acadêmico-profissional no campo científico da educação, o qual a autora ajudou a construir ao longo destes anos de XX e de XXI.

Lembro-me de ter coordenado editorialmente duas edições desta natureza. A primeira uma homenagem à Antônio Gouveia Mendonça', meu ilustre orientador e responsável por minha entrada na academia, que à época completava 70 anos e, era praxe, no mundo acadêmico, uma revisão da obra do jubilado. A segunda, à Vivaldo Paulo dos Santos², por ocasião da entrega de título de Professor Emérito - Educação, na Universidade Nove de Julho, coordenei um opúsculo sobre a sua obra. Este tipo de homenagem se faz por meio da leitura do conjunto da obra do autor/a, interpretando-a ou revisando-a no que concerne a sua contribuição ao Campo Científico do/a homenageado/a. Em ambas ocasiões vários colegas dos referidos campos fizeram uma leitura teórico-crítica das obras, destacando as contribuições dos autores ao campo que pertenciam. Agora me é dada esta nova oportunidade de editorar, nesta empreitada, uma leitura da obra de Marli André e sua contribuição para a área da Educação, realizada também por um conjunto de scholar nos campos investigativos da Didática e da Formação de Professores.

Foi deste lugar, do mundo acadêmico, que conheci Marli e sua incontestável importância para o campo que o autor deste editorial estava entrando, ou melhor, batendo à porta. Tinha me doutorado em 1997 e estava mudando de área por forças das circunstâncias do mundo do trabalho. Doutor em Ciências Sociais trabalhando

1 Revista Reformanda. Número especial, periódico publicado pela Faculdade Teologia de São Paulo. Reformanda, ano IV n.3, 1992

2 Ver. Jardilino, J.R.L, Almeida, C.R.S, Lauriti, N.C. Navegar é preciso - um tributo a Vivaldo Paulo dos Santos "Um professor Emérito". Universidade Nove de Julho, 2006. 


\section{autêntica}

DOI https://doi.org/10.31639/rbpfp.v28i13.557

\section{EDITORIAL}

em um mestrado na área da Educação na cidade de São Paulo. Foi aí que me encontrei com Marli, a primeira vez, nos corredores da Pontifícia Universidade Católica de São Paulo, depois nos seus textos e as contribuições para a pesquisa qualitativa, a pesquisa com etnografia escolar, com as quais já havia me deparado no campo das Ciências Sociais, desde os primórdios da minha formação inicial. Em 2008 em comemoração aos dez da Revista Eccos da qual era o editor (2000-2010), fazíamos uma leitura das pesquisas na área da educação, convidei Marli para escrever sobre "As pesquisas sobre a escola e no cotidiano da escola". Se tornou um texto celebrado na Eccos. Mais tarde, como todo inquieto iniciante em um campo científico, que aspira ser reconhecido pelos experts ${ }^{3}$ do referido campo e já tendo apresentado o meu primeiro trabalho no GT 08 -Formação de Professores - da Anped (porta de entrada para o campo), trabalhei com Marli. Á época estávamos empenhados no debate caloroso sobre o lugar que ocupava a Formação de Professores no conjunto de GTs da Anped e, mesmo na área da educação. Estabeleciam-se questionamentos se a Formação de Professores era um "tema" disperso nos diversos campos (hoje melhor compreendido pela pesquisa de Fernanda Astori, 2021), ou se tinha características específicas de um campo de estudo, um campo científico.

Como já vinha em trajetória inicial de formação nas Ciências Sociais, junto com Iria Brzeziski, também com a mesma formação inicial, nos propusemos a preparar alguns apontamentos sobre o campo específico da Formação de Professores. Iria já experiente pesquisadora e socióloga preparou com seu grupo o material. Eu, como iniciante busquei respaldo no grupo permanente no qual estava me inserindo, agindo como todo neófito em um determinado campo. Juntos então com Laurizete Passos, Marcia Hobold, e Marli André, buscamos trazer a reflexão para o GT, naturalmente partindo dos trabalhos já apresentadas no $\mathrm{GT}^{4}$, sobre a análise da produção da FP e inspirando ou criando hipótese da autonomia do campo no interior da grande área da Educação.

A minha insistência pela discussão sobre o "campo científico" tomou conta das nossas reuniões. Claro que não havia consenso, fizemos a tarefa preparamos o ensaio para apresentar na Reunião Anual da Anped. Fui, democraticamente, escolhido para apresentar o trabalho sozinho, até agora sem publicá-lo, embora usado, aqui e ali, como referência daquele trabalho encomendado naquela Reunião Anual da Anped de 2010.

“O relatório (no prelo) referente ao segundo simpósio elaborado por André, Brzezinski, Menga e Roldão (2010), caminha na direção da impossibilidade, neste momento histórico, da Formação de Professores se constituir como um "campo" de pesquisa, reclamando para isso a falta de limites ou fronteiras próprias da estruturação de um campo científico. Afirmam as autoras: "o estabelecimento dos limites ou fronteiras do campo destina-se a clarificar o objeto que se estuda focadamente, distinguindo-se de outros, embora sabendo que cada campo se inscreve na interface de outros campos que integram um sistema de conhecimentos mais vastos" (p.7). E concluem que "mais uma vez, constatou-se a impossibilidade de, neste momento histórico, traçar um delineamento do campo" (grifos nossos) (Jardilino, 2010, p.5)

Logo em seguida no mesmo ano saia no vol. 33 da revista da PUC. RS um dossiê sobre Formação de Professores, no qual a profa. André publicava um excelente ensaio que se tornou referência para o GT e para

3 Nas palavras de Bourdieu $(1976,89)$ “O campo científico como sistema de relações objetivas entre as posições adquiridas é o lugar (ou seja, o espaço de jogo) de uma luta competitiva que tem por interesse específico o monopólio da autoridade científica indissociável de capacidade técnica e de poder social, ou se preferir, o monopólio da competência científica, estendido no sentido da capacidade de falar e agir legitimamente (de forma autorizada e com autoridade) em matéria de ciência, que é socialmente reconhecida por um determinado agente" (tradução do autor)

4 Ver. ANDRÉ, M. (2002; 2010); ANDRÉ., et.al. (1999;2002); BRZEZINSKI, I, (2007). BRZEZINSKI, I; GARRIDO, E. (2002); ROLDÃO, M. (2009): TERRAZAN, E; GAMA, M.E. (2007); RAMALHO, B.L, et.al. (2000); VENTORIM, S. A (2005) 
área da Educação em geral. O ensaio era exatamente sobre "Formação de Professores: a Constituição de um Campo de Estudos. Ali pude perceber que de certa maneira havia discordância com a minha insistência da compreensão da Formação de Professores na perspectiva de um "Campo Científico", mais especificamente, parte do GT. A compreensão de "Campo de Estudos" para o GT se consolidou e ajudou muitíssimo a reflexão e as pesquisas posteriores.

Atualmente, estou mais próximo da construção teórica de Marli, em especial depois de ler a tese Astori (2021). Por outro lado, penso que a estrutura que Marli indicou no seu texto me permite ampliar a ideia de "campo" bourdieusiano, sem, todavia, desprezá-lo porquê ainda no momento presente há certa dubiedade sobre o assunto. Vejamos, a conclusão do próprio artigo de Marli (Andre, 2010), que embora resistindo o conceito de Bourdieu, aponta para todas as características intrínsecas próprias do conceito:

(...)Essas iniciativas da comunidade científica têm possibilitado que a área se torne mais respeitada frente às demais áreas de conhecimento, o que é fundamental para a constituição do campo, pois há disputas de poder entre as áreas e quanto mais o coletivo assumir posições claras e coerentes mais força terá para firmar-se como um campo autônomo (Andre, 2010, p.180)

O último elemento que faltava na sua estruturação teórica e analítica para se aproximar do conceito de "campo científico" era a questão da disputa no campo, não mencionada por Marcelo (1999), sua fonte mais específica para aquele artigo. Ao chegar a essa compreensão aponta para o elemento da legitimidade na arena científica dos outros campos. Ou na expressão de Bourdieu:

\footnotetext{
"La forme que revêt la lutte inésperablement politique et scienifique pour la légitimité scientifique dépend de la structure du champ, c'est-à-dire de la structure de la distribution du capital spécifique de reconnaissance scientifique entre les participants à la lutte (...) Le champ scientifique est toujours le lieu d'une lutte" (Bourdieu, 1976, p95/96) ${ }^{5}$.
}

Assim mesmo não tendo ainda, naquela ocasião, conhecimento do artigo publicado (André, 2010) as edições não estavam tão genericamente online como hoje, 10 anos depois - me propunha a conversar com o Gt a questão do campo, e o fiz numa mediação entre a minha rigidez conceitual bourdieusiana e a realista concepção do grupo como expressa no relatório do Simpósio do GT, publicado naquele mesmo ano. Diante da perspectiva apontada, e tendo como referencial a analise acima indicado, procurava compreende essa impossibilidade e apontava perspectivas quanto a estruturação do campo.

No que pese, o vigor da análise advinda de um olhar para a rica e diversa produção dos grupos reunidos no simpósio do GT, pretendi ponderar sobre a concepção de Campo e a sua estruturação no interior de uma área, e o fiz, trazendo o elemento com o qual Marli finalizou seu artigo, a questão do poder e as disputas na constituição e permanência de um campo científico.

Bourdieu defendeu sempre que o fazer ciência é uma tarefa crítica e reflexiva (2007), é manter uma constante "vigilância epistemológica" para afastar a possibilidade de enxergar o real com "olhos míopes", justamente por que os objetos de estudo das ciências humanas estão muito próximos do cotidiano dos investigadores (2004, p.24). Uma das características que distinguiu Bourdieu dentro das Ciências do Social foi o emprego

\footnotetext{
5 "A forma que assume a luta inevitavelmente política e científica pela legitimidade científica depende da estrutura do campo, isto é, da estrutura da distribuição do capital específico de reconhecimento científico entre os participantes da luta (...) o campo científico é sempre um lugar de luta” Bourdieu 1976, pp 95/96)
} 


\section{autêntica}

DOI https://doi.org/10.31639/rbpfp.v28i13.557

da teoria rigorosa como observação sistemática da realidade. Isso posto nos leva a considerar a ideia de campo científico do autor, creio que a mesma que tinham em mente as autoras do relatório final daquele simpósio, para afirmar a impossibilidade no momento de considerar a formação do professor como um campo científico de pesquisa.

Não se pode fugir da concepção Bourdieusiana de campo como espaços estruturado de posições sociais e de poder onde se produz e consome determinados bens/objetos. Um espaço de jogo onde as relações dos indivíduos e instituições são mediadas pela disputa de um tipo de capital ou "energia social" monitorada no próprio interior de um referido campo. Ao tratar do campo científico, como nos demais (literário, moda, religião, educação) Bourdieu coloca em cena as questões de poder vivenciadas numa luta social na busca pela distinção e reconhecimentos por parte dos integrantes de um determinado campo. Assim o campo científico é um campo como outro qualquer, com suas lutas internas, relações de forças e monopólios. O produto especial deste campo é o capital social medido pela capacidade técnica e teórica que precisa ser reconhecida pelos mandarins do campo - a autoridade científica que confere prestígio e reconhecimento, valida o conhecimento dentro do campo.

As propriedades de um campo, além do habitus específico, são a estrutura, a doxa, ou a opinião consensual as leis que o regem e que regulam a luta pela dominação do campo. Aos interesses postos em jogo, Bourdieu denomina "capital" - no sentido dos bens econômicos, mas também do conjunto de bens culturais, sociais, simbólicos etc. Como nos confrontos político ou econômico, os agentes necessitam de um montante de capital para ingressarem no campo e, inconscientemente, fazem uso de estratégias que lhes permitem conservar ou conquistar posições, em uma luta que é tanto explícita, material e política, como travada no plano simbólico e que coloca em jogo os interesses de conservação (a reprodução) contra os interesses de subversão da ordem dominante no campo.

Neste aspecto, o funcionamento do campo científico deixa transparecer que as escolhas não são desinteressadas, sabemos que todas as escolhas epistemológicas e metodológicas são escolhas políticas. Determinar os contornos de um campo é uma escolha política. Conforme explicita o autor:

Il n'est pas de choix scientifique, choix du domaine de recherche, choix de méthodes employées, choix de lieu de publication...qui ne soit, par un de ses aspects, le moins avoué et le moins avouable évidemment, une estratégie politique du placement au moins ebjectivement orientée vers la maximisation du profit proprement scientifique, c'est-à-dire de la reconnaissence susceptible d'être obtnue des pairs-coucurrents ( Bourdieu 1976, p.91) ${ }^{6}$

Diante da leitura feita à época, provoquei o grupo com base em Bourdieu com a seguinte assertiva "desta maneira, podemos permanecer no estágio atual, até o esgotamento das nossas produções minimalistas sobre a formação de professores e a desintegração de uma temática que jamais virá a constituir o campo teórico". Na condição de recém-chegado ao campo, conforme a leitura bourdieusiana, tinha interesse em alterar algumas regras e disposições (epistemológica e praxiológica) para que os novos pudessem ser valorizados dentro do campo, claro que isto só ocorre em negociação com os pares concorrentes e o reconhecimento das autoridades científicas de um campo.

6 "Não há escolha científica, escolha do campo de pesquisa, escolha dos métodos empregados, escolha do local de publicação (...) que seus aspectos, menos confessado ou menos confessável, evidentemente, não seja uma estratégia política de investimento, pelo menos objetivamente orientado para a maximização do lucro estritamente científico, ou seja, de um provavel reconhecimento obtido dos pares-concorrentes. (tradução do autor) 


\section{autêntica}

DOI https://doi.org/10.31639/rbpfp.v28i13.557

O que à época procurávamos apresentar era o reconhecimento e os contornos daquilo que poderá ou não se constituir um campo de pesquisa científico. E isso não estava isolado, mas expresso nas diversas análises de levantamentos, diagnósticos e estado da arte produzidos no e para compreender as fronteiras daquilo que nos constituiria como campo. Estou falando da "vigilância epistemológica" que nos adverte Bourdieu.

Pensando, pois, na diversificação e na elasticidade do "Campo" no GT08 nos pareceu que não era possível concretizá-lo de um "campo científico", ao contrário a elasticidade dos "Estudos" sobre a formação de professores e as respectivas instituições formadoras, levaram-no a uma reflexão sobre seu papel e os contornos do seu campo na linha limítrofe com os demais subcampos da educação, nos quais Marli André foi uma das grandes responsáveis pelo amadurecimento do debate.

Isso historicamente se deu, quando na década de 1990 pela entrada de novas temáticas relacionadas da formação e sua hegemonia no campo educacional, levou o GT a reconfigurar-se para dar guarida aos recém-chegados ao campo, reconhecendo que não somente a denominação do GT, mais a seu enquadramento teórico-metodológico já não dava conta de examinar e compreender o fenômeno. Estabelece uma moldura do campo o que cabe chamar de "Formação de Professor". É então mediante uma recomposição de temáticas que o GT abriga uma série de subtemáticas em torna da formação de professor, desestrutura um campo já consolidado - As licenciaturas - transformando-se posteriormente no maior GT e numa ecologia multifacetada de tendências teóricas e metodológica que se reúne no que chamamos Formação de Professor. Fazia-se necessário articular, pelo menos, uma moldura para o quadro "formação de professor".

Diante de tal elasticidade do campo, os levantamentos e estados da $a^{7}{ }^{7}$ que indicavam algumas fragilidades e perda da vigilância epistemológica, destinação investigativa mais direcionada a um percurso "praxiológico ${ }^{8 "}$ dentre outros, levaram-nos a repensar a questão do "campo" investigativo que ocupamos dentro do "campo maior" - a Educação.

A impossibilidade de considerar a F.P como Campo de pesquisa têm origem nas problemáticas referidas e referenciadas nos vários levantamentos realizados. Mas, ali apontou-se uma necessidade de continuar pensando o campo. Talvez fosse possível pensar nos seus contornos, na sua moldura, como um quadro, assumindo mais diretamente os imperativos da teoria de Bourdieu de Campo Científico.

Finalizo este editorial, afirmado que nossa colega Marli André, que tem neste número uma expressiva reflexão sobre a sua obra, foi uma intelectual constituinte do "campo" da Formação de Professores e exerceu autoridade, outorgada pelos próprios pares do campo, porque esta autoridade científica estava inseparavelmente ligada à sua competência científico-acadêmica e representação social na área da Educação que exerceu até sua morte. 


\section{autêntica}

DOI https://doi.org/10.31639/rbpfp.v28i13.557

\section{REFERENCIAS CITADAS:}

ANDRE, M, SIMOES, R.H.S., CARVALHO, J.M. et al. Estado da Arte da Formação de Professores no Brasil. Educ.Soc. vol 20, n.68 p 301-3009, 1999.

ANDRE, Marli E. D. A. Pesquisas sobre a escola e pesquisas no cotidiano da escola EccoS Revista Científica, vol. 10, julho, 2008, pp. 133-145 Universidade Nove de Julho São Paulo, Brasil

ANDRE, M. (2010). ANDRÉ, M. Formação de Professores:a Constituição de um Campo de Estudos. Educação, v. 33, n. 3, 19 dez. 2010. Recuperado de https://revistaseletronicas.pucrs.br/ojs/index.php/faced/article/view/8075

ANDRÉ, M.(org.) Formação de professores no Brasil (1990-1998). Brasília: MEC/INEP/COMPED, 2002. (série Estado do Conhecimentos, $n^{\circ}$ 6).

ANDRÉ, M. E. D. A.; LÜDKE, M.; ROLDÃO, M. DO C. Pesquisa sobre Formação de Professores: Síntese do II Simpósio de grupos de pesquisa do GT 8 da ANPEd. Formação Docente - Revista Brasileira de Pesquisa sobre Formação de Professores, v. 2, n. 3, p. 152-159, 18 dez. 2010.

ASTORI, F.B. da Silva. Aproximações epistemológicas praticadas nos trabalhos da Anped sobre formação continuada de professores (2008-2019). Tese de Doutorado em Educação. Universidade Federal do Espírito Santo, Vitória, 2021.

BOURDIEU, P. Le Champ Scientifique. In Actes de la Rcherche en Siences Sciales. Vol.2, n 2,3 juin 1976 pp, 88-104

BRZEZINSKI, I. Pesquisa sobre formação de Profissionais da educação em 25 anos de história. In. $30^{a}$ Reunião Anual da Anped, 2007. (Trabalho Encomendado GT 08)

BRZEZINSKI, I; GARRIDO, E. Os trabalhos do GT Formação de Professores da Anped. In. ANDRÉ, M.(org.) Formação de professores no Brasil (1990-1998). Brasília: MEC/INEP/COMPED, 2002. (série Estado do Conhecimentos, $\left.n^{\circ} 6\right)$.

JARDILINO, J.R.L. et.al. Contornos de um campo de pesquisa: considerações a partir da produção sobre Formação de Professores divulgada no GT 08 da ANPED, 2000-2010. In. REUNIÃO ANUAL DA ANPED. Trabalho Encomendado GT08 - RA34 Natal, 2011.

ROLDÃO, M. do C - A formação de professores como objecto de pesquisa - contributos para a construção do campo de estudo a partir de pesquisas portuguesas. Revista Eletrônica de Educação. São Carlos, SP: UFSCar, v.1, no. 1, p. 50-118, set. 2007. Disponível em http://www.reveduc.ufscar.br.

ROLDÃO, M. do C Formação de professores na investigação portuguesa - um olhar sobre a função do professor e o conhecimento profissional. In. Rev. Bras. Form. Doc., Belo Horizonte, v. 01, n. 01, p. 57-70, ago./ dez. 2009. 57 Disponível em http://formacaodocente.autenticaeditora.com.br

RAMALHO, B. L, et.al. A pesquisa sobre a formação de professores nos programas de pós-graduação em educação: o caso do ano 2000. In. $25^{a}$ Reunião Anual da Anped, 2002. (trabalho encomendado Gt 08)

TERRAZAN, E; GAMA, M.E. Características da formação continuada de professores nas diferentes regiões do país. In. 30ª Reunião Anual da Anped, 2007

VENTORIM, S. A formação do professor pesquisador na produção científica dos encontros nacionais de Didática e Prática de Ensino: 1994-2000. In. 28ª Reunião Anual da Anped, 2005.

Gatti, B. A., A pesquisa em Educação e o campo da formação de educadores: diálogos com Marli André. Formação Docente - Revista Brasileira de Pesquisa sobre Formação de Professores. Belo Horizonte. Vol. 13, nº 28 (p. 9-14) 31 dez. 2021. ISSN: 2176-4360. DOI https://doi.org/10.31639/rbpfp.v28i13.557 


\title{
APRESENTAÇÃO
}

\section{Marli André - A pesquisa qualitativa em educação e formação de professores}

\begin{abstract}
Esse número especial "Marli André - a pesquisa qualitativa em educação e formação de professores", tem por finalidade expressar o reconhecimento da comunidade de pesquisadores em educação e do Grupo de Trabalho - GT 8 (Formação de Professores), da Associação Nacional de Pesquisa e Pós-Graduação em Educação - ANPEd Nacional, quanto às contribuições teórico-metodológicas de Marli André para a pesquisa em Educação e para o campo da formação de professores.
\end{abstract}

Entre as muitas homenagens aqui prestadas, pesquisadores brasileiros que conviveram com Marli André em projetos de pesquisa, órgãos de fomento, associações de pesquisadores, e ainda como orientandos, expressam seu tributo de reconhecimento das parcerias estabelecidas na realização de pesquisas em educação, e em especial em formação de professores.

Acentuamos esta edição especial será dedicada a trajetória de Marli André em sua atuação de colaboração e cooperação na ANPED. Ressaltado que a trajetória da autora está amalgamada na própria história da associação. Sua atuação e participação intensa fortalecem seu reconhecimento por essa comunidade de intelectuais e pesquisadores. Na ANPED Marli Andre foi membro da diretoria em seus conselhos, realizou conferência de encerramento e foi coordenadora de GT. Marcadamente, no GT 08 Formação de Professores, Marli dedicou-se intensamente e sua presença qualificava as muitas ações das quais participou como: comunicações nas reuniões nacionais e regionais, realização de mini curso, trabalhos encomendados, parecer em trabalhos, participação na organização das reuniões sugerindo assuntos a serem discutidos, pesquisadores a serem convidados, além de presença cativa durante a realização das reuniões contribuindo com os pesquisadores com sugestões e observações.

Registramos seu intenso compromisso nos Simpósios dos Grupos de Pesquisa em Formação de Professores desde o momento das primeiras conversas sobre sua criação, suas considerações expressas de modo arguto e perspicaz nas análises, compondo o comitê avaliador. Suas densas ponderações nas sessões de encerramento dos grupos de pesquisa são contribuições preciosas no compósito do campo de formação de professores e para a formação em pesquisa.

Destacamos, também, no Gt de Formação de Professores o seu forte apoio à criação da "Formação Docente" - Revista Brasileira de Pesquisa sobre Formação de Professores. Desde as primeiras conversas Marli sempre presente sugerindo para a definição do escopo da revista, compondo o Comitê Consultivo Editorial, realizando avaliação dos artigos e, em especial, publicando artigos.

As contribuições de Marli André não são restritas à Anped e ao GT 08 Formação de Professores, são sim amplas em diferentes instituições universitárias na graduação e na pós-graduação, como pesquisadora, professora, orientadora, coordenadora, membro de diretorias, comissões, uma vida acadêmica intensa. 


\section{autêntica}

DOI https://doi.org/10.31639/rbpfp.v13i28.558

Além disso, atuou em órgãos de fomento, fundações de pesquisas, órgãos governamentais, entre outros. A intensidade de sua contribuição é inegável para a pesquisa, para a ciência, para a gestão e para a formação de professores e pesquisadores. Assim, os artigos aqui publicados constituem testemunhos dessa trajetória ímpar na pesquisa em educação.

Participam deste número especial Menga Ludke, com uma homenagem especial, Reverberações da nossa Estrela Marli André. Menga e Marli desenvolveram uma parceria intensa na vida, em projetos de pesquisa, em publicações e debates da área. Em seu artigo, Menga Ludke explora aspectos da trajetória escolar e profissional de Marli André pouco divulgados e que revelam as bases de todo o seu envolvimento com a área da Educação e da pesquisa qualitativa. Destaca, em especial, a preocupação de ambas com a busca de uma concepção de pesquisa que acolhesse novas estratégias e modalidades e que ampliasse o modo de ver a pesquisa em educação e na formação de professores.

Em seguida Lucidio Bianchetti apresenta uma entrevista realizada com Marli André. Como indica o autor a entrevista foi desenvolvida a partir de um roteiro organizado dentro de três eixos: formação e carreira do líder; sua condição de líder do Grupo (tempo, liderança, atuação); e seu entendimento sobre três questões centrais, a saber: como avalia a importância do Grupo no processo de formar orientadores? Em que indicadores sustenta a sua avaliação? Considera o grupo de pesquisa como um locus de formação e de atuação de orientadores? A entrevista, foi feita nas dependências da PUC/SP, no dia 11 de agosto de 2017, com duração de $1 \mathrm{~h} 15 \mathrm{~min}$. Após transcrita, foi encaminhada à professora Marli que a revisou. Assim, consideramos essa entrevista como um depoimento precioso para compor este dossiê.

Na sequência, Bernadete Angelina Gatti, também companheira de pesquisas e labutas acadêmicas, traz em seu artigo reflexões resultantes dessa vivência e questões relacionadas ao emprego dos métodos qualitativos na pesquisa em educação e na formação de educadores. Destaca os diálogos mais diretos com Marli, especialmente os relacionados aos desafios teóricos e metodológicos enfrentados em estudos de larga escala nas pesquisas de campo e estudos de caso. Explora outros temas caros à pesquisadora: a concepção de professor-pesquisador e a ideia de pesquisa como formação.

O texto de Maria Rita N. S. Oliveira, resultado de marcas da longa convivência com Marli André, aborda aspectos da sua obra que revelam seu compromisso com uma educação socialmente referenciada, na Didática e na Formação de Professores. Destaca princípios e valores com os quais construiu seu trabalho, particularmente nesses dois campos. Explora o conjunto da sua produção intelectual como fonte para o contínuo desenvolvimento do conhecimento científico teórico-prático. Sintetiza e analisa os principais aspectos dessa produção: Coerência no compromisso com a inclusão educacional; Pesquisa como fator de organicidade e a interação entre Didática e Formação de Professores; Ênfase na pesquisa etnográfica e Participação expressiva na constituição histórica da Didática e da Formação de Professores e os estudos integrativos

Eurize Caldas Pessanha, como pesquisadora do campo da História da Educação, apresenta a partir da organização da produção bibliográfica de Marli André, como conceitos, temáticas, referências, relações, cruzamentos e ausências são evidenciados e revelam as contribuições e a trajetória de sua participação destacada e significativa em todas as etapas da história da pesquisa educacional e da produção do conhecimento sobre a educação no Brasil. Pelo legado deixado, pelas ideias disseminadas e influências para áreas de Didática, Prática e Formação de Professores e para a Pesquisa Qualitativa, a pesquisadora traz evidências do que chamou "o legado da mulher intelectual Marli André".

Maria do Céu Roldão que destaca suas interações com Marli estabelecidas há quase 30 anos, iniciadas num congresso da AFIRSE, realizado na Universidade de Lisboa. Diz a autora que neste encontro "foi o início de 
uma profunda amizade e de uma colaboração regular que me liga a ambas, no caso de Marli tragicamente interrompida no início deste ano de 2021. Este texto, que lhe dedico, procura carregar em si muito do que aprendi com ela, textos que produzi a pedido dela no Gt8 da ANPEd em que me honrou com seus frequentes pedidos de colaboração, ideias - muitíssimas - que aprofundámos juntas, debatemos e ampliámos."

Pura Lúcia Oliver Martins e Neuza Bertoni, para seu artigo, selecionaram um conjunto de artigos publicados em diferentes periódicos nacionais para situar os caminhos percorridos por André. Destes textos destacam os problemas apontados a serem superados na produção de conhecimentos sobre a pesquisa qualitativa e os inúmeros desafios que a pesquisadora destacou em sua trajetória, especialmente aqueles decorrentes das dúvidas e soluções identificadas na formação de pesquisadores da área da educação.

Emilia Freitas de Lima, nas contribuições da professora Marli André para a produção de conhecimento sobre professores iniciantes, destaca as principais produções acadêmicas da homenageada sobre o estudo dos professores iniciantes. Para a composição do texto, Lima considerou todas as produções de Marli André sobre o assunto, em especial as discussões relativas à elaboração de políticas públicas, em que se evidencia a crítica às autoridades governamentais e das agências de fomento à pesquisa por alegarem a ausência de contribuição de pesquisadores e pesquisadoras brasileiras para com os professores iniciantes que carecem de programas de apoio para sua inserção e atuação profissional, como bem destacam os estudos e investigações.

Romilda Teodora Ens que juntamente com sua orientanda Jaqueline S. Oliveira Nagel, sublinham as contribuições de Marli André quanto aos sentidos e significados expressos num conjunto de obras direcionadas a apontar a relação entre a pesquisa e a formação de professores como "constantes sociais" que contribuíram para a definição do campo da formação de professores e formação de professores no Brasil. As autoras também destacam a participação de Marli André no Congresso Nacional de Educação - Educere, realizado na Pontifícia Universidade Católica do Paraná (PUCPR), nas edições de 2004 a 2019.

Ao finalizarmos esta apresentação deste número especial da RBPFP, expressamos nosso profundo agradecimento à Marli, por sua amizade, companheirismo, acolhimento. Marli nosso arrimo na formação para a pesquisa, para a compreensão dos processos teóricos metodológicos necessários à investigação, nossa orientadora instigando para a reflexão sobre as problemáticas e desafios da área da educação e sobretudo do campo da formação de professores.

Agradecemos aos(as) pesquisadores(as) que carinhosamente acolheram o convite para contribuir com a realização desta leitura do legado acadêmico da profa. Dra. Marli Eliza Dalmazo Afonso de André e convidamos os (as) leitores(as) para esta inserção na obra da autora homenageada.

Coordenação Editorial

Joana P Romanowski

Márcia Hobold

Laurizete Ferragut Passos

ROMANOWSKI, J.P.; HOBOLD, M.; PASSOS, L.F.; Apresentação. Formação Docente - Revista Brasileira de Pesquisa sobre Formação de Professores Vol. 13, nº 28 (p. 15-18) 31 dez. 2021 
